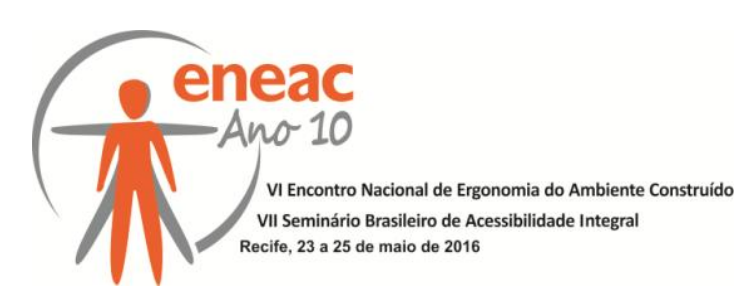

\title{
ANÁLISE DA AMBIÊNCIA EM TEMPLO ECUMÊNICO
}

\author{
BECK, Luciana Mota (1); \\ NOEBAUER, Marlise Paim Braga (2); \\ BULA, Natalia Nakadomari (3); \\ ALMEIDA, Maristela Moraes de (4).
}

(1) Universidade Federal de Santa Catarina, Doutoranda PósARQ/UFSC.

e-mail: lumotabeck@gmail.com

(2) Universidade Federal de Santa Catarina, Mestranda PósARQ/UFSC.

e-mail: arquiteta@lisenoebauer.arq.br

(3) Universidade Federal de Santa Catarina, Mestra em Arquitetura e Urbanismo PósARQ/UFSC.

e-mail: arq@nataliabula.com

(4) Universidade Federal de Santa Catarina, Doutora em Engenharia de Produção, Docente do Curso de Graduação em Arquitetura e Urbanismo UFSC.

e-mail: arqtela.ma@gmail.com

\begin{abstract}
RESUMO
Espaços para fins ecumênicos devem oferecer um local de paz, tranquilidade e reflexão. Para tanto, devem atender às necessidades de usuários das mais variadas crenças, tornando-o funcional e agradável para seu uso. O caráter da arquitetura é conferido pelo equilíbrio entre as questões objetivas e subjetivas da ambiência, e interfere nas sensações e percepção dos usuários. Este trabalho apresenta um estudo sobre o Templo Ecumênico da Universidade Federal de Santa Catarina, baseado na "Teoria dos Conflitos" e analisa as interações entre os usuários e o ambiente, identificando elementos arquiteturais e os conflitos reveladores de fenômenos existenciais da ambiência.
\end{abstract}

Palavras chave: ambiência; arquitetura, teoria dos conflitos; elementos arquitetônicos.

\begin{abstract}
Espaços para fins ecumênicos devem oferecer um local de paz, tranquilidade e reflexão. Para tanto, devem atender às necessidades de usuários das mais variadas crenças, tornando-o funcional e agradável para seu uso. O caráter da arquitetura é conferido pelo equilíbrio entre as questões objetivas e subjetivas da ambiência, e interfere nas sensações e percepção dos usuários. Este trabalho apresenta um estudo sobre o Templo Ecumênico da Universidade Federal de Santa Catarina, baseado na "Teoria dos Conflitos" e analisa as interações entre os usuários e o ambiente, identificando elementos arquiteturais e os conflitos reveladores de fenômenos existenciais da ambiência.
\end{abstract}

Keywords: ambiência; arquitetura, teoria dos conflitos; elementos arquitetônicos. 


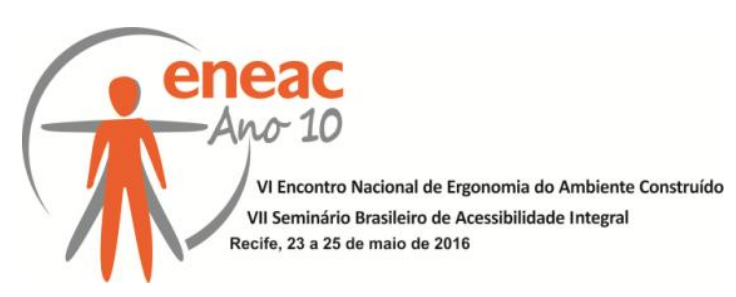

\section{INTRODUÇÃO}

O Brasil é um país cada vez mais pontuado por diversidade religiosa e também por distintas opções espirituais, religiosas ou não. Espaços para elaboração de iniciativas ecumênicas e inter-religiosas em centros universitários promovem a sensibilidade ecumênica para grande número de alunos, funcionários, professores e também para a comunidade local, proporcionando ambientes de diálogo e conhecimento.

Estes espaços devem atender às necessidades de seus usuários e oferecer um local de paz, tranquilidade e reflexão. Para tanto, é necessário atentar para um conjunto de fatores para torná-lo funcional e agradável para seu uso.

Assim, este trabalho apresenta um estudo sobre a ambiência no templo Ecumênico da Universidade Federal de Santa Catarina - UFSC, com o intuito de analisar as interações entre os usuários e o ambiente. Os conflitos provenientes dessa relação foram identificados (MALARD, 1992), revelando fenômenos existenciais da ambiência não satisfeitos por elementos arquitetônicos inadequados ou ausentes no templo.

\section{MÉTODO UTILIZADO: TEORIA DOS CONFLITOS}

Desenvolvida por Malard (1992) em sua tese de Doutorado, a teoria dos conflitos arquitetônicos parte da distinção que Heidegger (1997) faz sobre as coisas serem "presentto-hand" ou "ready-to-hand". O primeiro termo diz respeito a "o que é?", à substância do objeto sem uma relação prática. O segundo é a função prática da ferramenta ou equipamento, "para quê serve?", a resposta desta pergunta é o "in-order-to" do objeto, a relação do equipamento e seu propósito.

A arquitetura é um equipamento "in-order-to" habitar, envolvendo diversas atividades, por exemplo, uma residência é para morar, um escritório para trabalhar, um templo para orar. Isto pode ser analisado em diversas escalas. Em uma escala menor, um dormitório tem o propósito de descansar e dormir, guardar os pertences pessoais e, dependendo do modo de vida pessoal, pode incluir outros propósitos. Mais detalhadamente, as portas, as janelas, as paredes, a cobertura, o mobiliário, cada um destes elementos tem seus propósitos, e até mesmo cada componente destes elementos tem seu propósito, por exemplo, a maçaneta da porta, o trilho ou o puxador de um móvel.

Quando algo não possibilita o desenvolvimento adequado "in-order-to" uma atividade (seu propósito), este equipamento é considerado "unready-to-hand". Sendo assim, os conflitos são caracterizados pela ausência ou inadequação de elementos arquitetônicos às atividades humanas. Utilizando a teoria dos conflitos é possível analisar os elementos arquitetônicos e identificar os conflitos reveladores de fenômenos existenciais da ambiência. Por exemplo, uma parede tem o propósito de separar ambientes, propiciando privacidade, então neste caso se a parede fosse substituída por um material translúcido, não estaria cumprindo com seu propósito, e mesmo se for uma parede opaca de pouca espessura, cumprirá com a privacidade visual, mas pode não ser adequada quanto à acústica, pois, quem sabe, seria possível escutar os ruídos do cômodo adjacente.

A teoria dos conflitos (MALARD, 1992; ALMEIDA, 1995) utiliza o procedimento de leituras espaciais a partir de observação sistemática direta dos fenômenos existenciais provenientes da inter-relação pessoa-ambiente. Estes fenômenos são registrados através de croquis, fotografias e relatos de usuários, podendo ser complementada apenas com pesquisa etnográfica. 


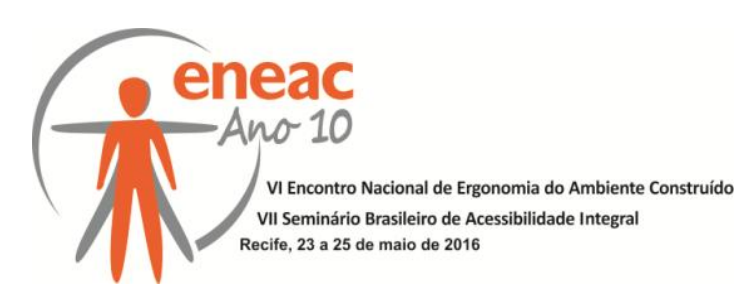

\section{AMBIÊNCIA}

Os fenômenos existenciais revelados através de conflitos observados na interação entre usuário e ambiente são territorialidade, privacidade, identidade e ambiência (ALMEIDA, 2001). Almeida (2001), sintetiza os seus conceitos, apontando que: a territorialidade é um fenômeno ligado à demarcação territorial na busca do espaço pessoal, a privacidade objetiva controlar os eventos interpessoais e a identidade se caracteriza pela personalização dos espaços pelo indivíduo.

Segundo Marlard (2006), a ambiência pode ser definida como o conjunto de fatores que tornam um ambiente agradável. Relaciona-se às qualidades do interior, constituindo um meio físico e estético-psicológico, preparado para o exercício de atividades humanas. Uma boa ambiência torna um espaço receptivo e propício ao convívio. A ambiência engloba os demais fenômenos - identidade, privacidade e territorialidade (ALMEIDA, 2014), manifestando-se em duas dimensões. Os aspectos subjetivos segundo seu caráter mais condicionado à cultura, aos costumes e à moda, e os objetivos, mais condicionado à fisiologia humana, como o conforto térmico, acústico, visual e antropométrico e/ou dimensional (MALARD, 2006).

A ambiência é o meio pelo qual cores, materiais, forma e textura são combinados no ambiente construído. Malard (2006) aponta que para Baudrillard (1996), a ambiência revela aspectos do chamado 'estilo de vida', ou seja, ajustado com o gosto de cada pessoa. Podese dizer que a ambiência é revelada no processo de apropriação do espaço, segundo as necessidades de desejos dos usuários. Segundo Heidegger (1971), é um processo sem fim de construir, arranjar, arrumar, modificar, cuidar e embelezar os lugares. Nesse processo 0 homem se apropria dos espaços, humanizando-os, modificando-os para dotá-los de sua natureza. A ambiência do ambiente permite que as pessoas se sintam em perfeita harmonia nos lugares e nos quais elas encontram sua identidade individual e coletiva.

Em relação aos elementos da ambiência, é possível classificá-los em: fixos, por exemplo, pisos, paredes de alvenaria, esquadrias, forros, semifixos, onde um bom exemplo são as cortinas e, móveis, tipificados por mobiliário e equipamentos (ALMEIDA, 1995).

\section{TEMPLO ECUMÊNICO}

Templo Ecumênico é um espaço destinado à realização de cerimônias de cunho religioso não específico, sendo um espaço neutro, onde independentemente do credo, os usuários possam expressar sua religiosidade. De caráter universal, devem abranger dimensões geográficas (se entende a todos os lugares), cultural (envolve os povos de diversas culturas ou modos de viver), política (considera todos os povos, independentemente do sistema político em que vivam), gênero (supera as discriminações de gênero), social (supera as discriminações sociais e de classe), e racial (supera as discriminações raciais).

O Templo Ecumênico da UFSC foi projetado em agosto de 1995, pelo arquiteto Jaime Kuck para ser um local de promoção da espiritualidade da comunidade. Tem capacidade para acomodar aproximadamente 300 pessoas sentadas e possui $370,24 \mathrm{~m}^{2}$ de área construída, que somada a 130,71 $\mathrm{m}^{2}$ de pergolado, perfaz uma área de $500,95 \mathrm{~m}^{2}$, onde são realizados cultos, formaturas, velórios, cursos e outros eventos religiosos.

\section{COMPREENDENDO O PROJETO}

A Figura 1, disposta a seguir apresenta a planta baixa do templo com a setorização dos espaços, segundo as atividades neles desenvolvidas (Figura 1a) e ilustra o caminho percorrido pelas pesquisadoras na abordagem experiencial do espaço, indicando os locais e direção das fotografias (Figura 1b). 


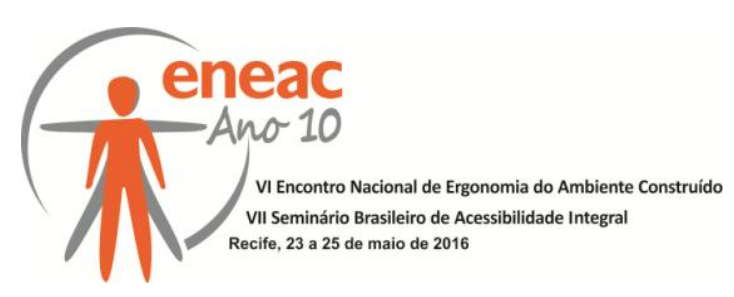

Figura 1 - Planta baixa.

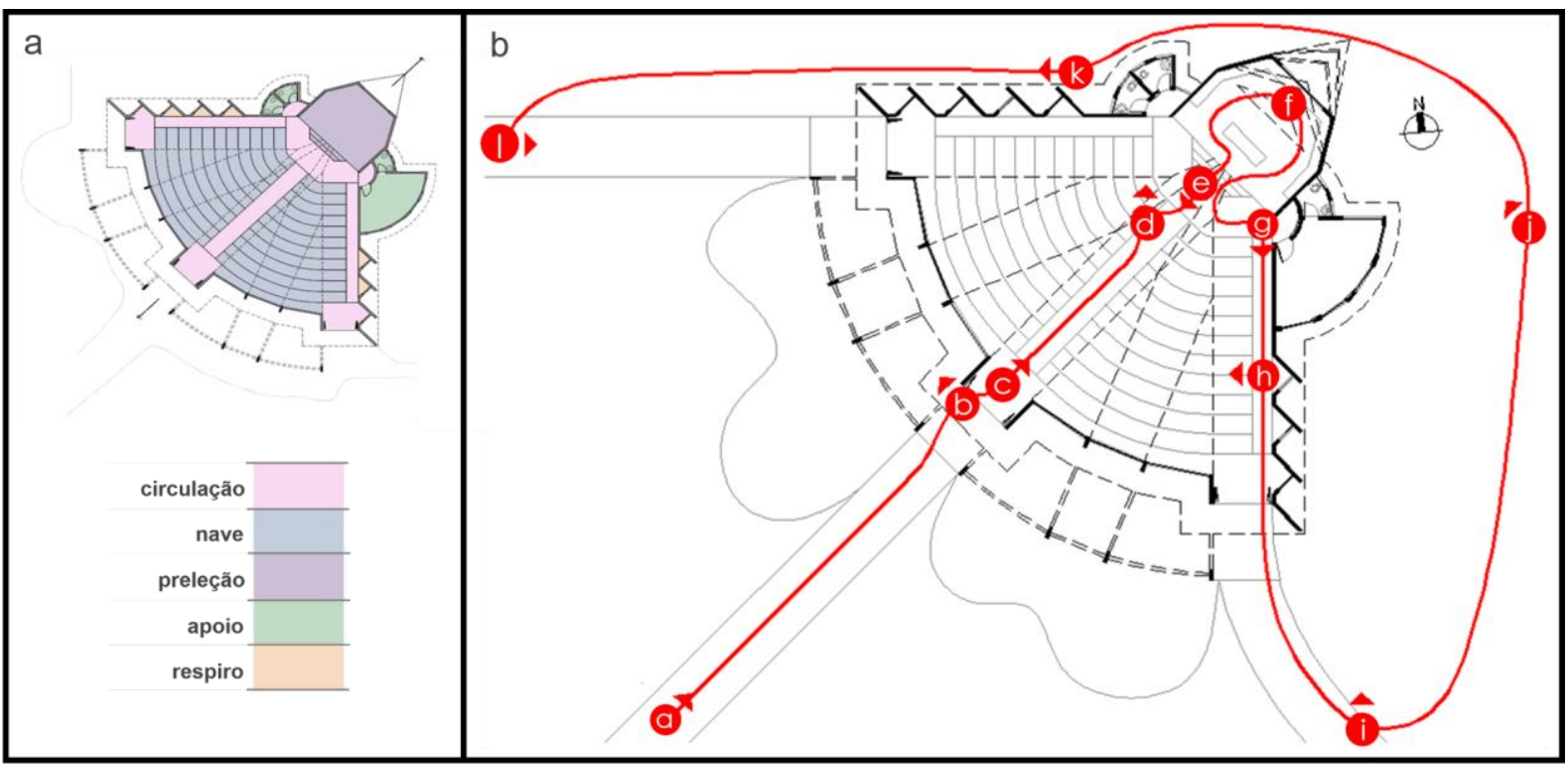

Fonte: elaborada pelas autoras, 2014.

O templo é bem discreto em relação às escalas da vegetação circundante e aos edifícios do entorno. Não é possível vê-lo por completo de nenhum ângulo devido às copas das árvores, fazendo surgir um sentimento de curiosidade, propiciando a aproximação do transeunte.

Aproximando-se a partir de seu acesso principal, em pedra portuguesa, observa-se um edifício branco, com grandes aberturas, simétrico, com predomínio da horizontalidade e cobertura composta por triângulos (Figura 2a). Antes de cruzar a porta de entrada há um espaço de transição - um pergolado - composto por vigas apoiadas em pilotis retangulares equidistantes ao longo da fachada principal. Apenas o desenho sinuoso do piso quebra com a regularidade das linhas (Figura $2 b$ ).

No interior, há a mesma simetria, bancos em madeira escura e pés de ferro com pintura preta, combinando com o detalhe em granito dos patamares onde estão distribuídos, formando um arco e tendo como ponto focal, ao fim da rampa, o altar, com o piso do mesmo granito e em nível elevado por três degraus. As paredes brancas e o piso cinza dão ar sóbrio ao ambiente, a laje sanfonada quebra a monotonia. O destaque, porém, fica com os vitrais coloridos, que filtram a luz natural e criam uma atmosfera acolhedora (Figura 2c). As aberturas ao lado do altar dão acesso à direita, à uma sala de apoio aos sacerdotes, que conta também com um banheiro, e à esquerda, a dois banheiros para uso da comunidade (Figura 2d). Ao dirigir o olhar para o acesso principal, a partir da base da rampa, se vê os vitrais triangulares, formados pelo desenho da laje, assim como todas as esquadrias quadriculadas e os bancos distribuídos ao longo do arco (Figura 2e). Ao subir no altar é possível ver todos os vitrais que compõem esta área e o pé direito alto causa sensação de amplitude. As aberturas zenitais com vidros fixos e transparentes permitem ver as copas das árvores no exterior, criando uma relação com a natureza (Figura 2f). Ao percorrer um dos corredores laterais em direção à saída, percebe-se o ritmo dos bancos de um lado, e a parede como um grande elemento linear do outro (Figura $2 \mathrm{~g}$ ). Mas olhando a partir daí para a nave, se pode ver toda a área dos bancos. Este é o ponto de onde melhor se vê o layout de distribuição, a localização das aberturas inundando o ambiente de luz e a irregularidade da laje (Figura $2 \mathrm{~h}$ ).

Já no exterior, fica mais fácil compreender sua forma (Figura 2i), exceto pelo detalhe mais simbólico do Templo, o qual exige certo grau de abstração. O volume do altar é configurado 


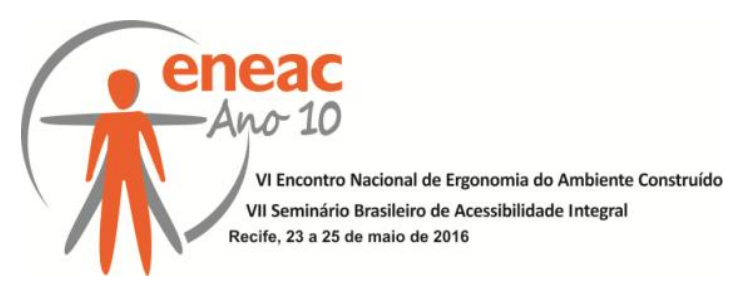

por duas mãos dispostas de forma a orar, e os vitrais são resultado do vão entre os dedos (Figura 2j). A mesma sensação de ritmo e fechamento é vista na lateral externa da capela (Figura 2k) e o afastamento pela outra lateral do edifício completa o passeio com uma vista dos triângulos da cobertura e seus vitrais (Figura 2l).

Figura 2 - Registros da abordagem experiencial.

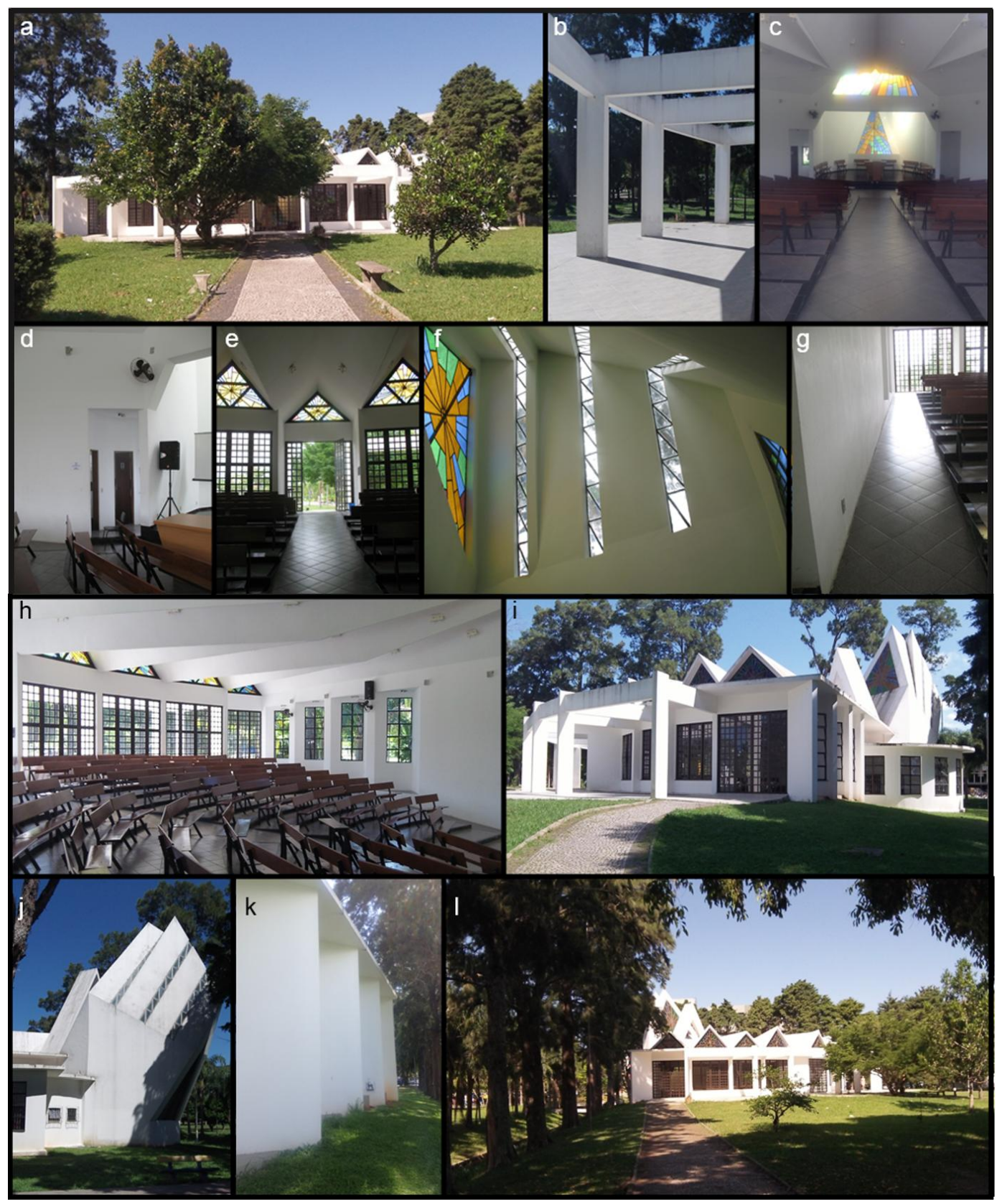

Fonte: elaborada pelas autoras, 2014.

\section{ANÁLISE DOS ELEMENTOS ARQUITETURAIS}

A seguir, serão descritos, de acordo com a classificação proposta por Almeida (2001), os elementos arquiteturais analisados e os conflitos reveladores de fenômenos existenciais da ambiência. Os elementos foram distribuídos em: elementos externos (forma, acessos e aberturas) e de interiores (distribuição do layout, mobiliário, equipamentos, iluminação artificial, materiais e revestimentos). 


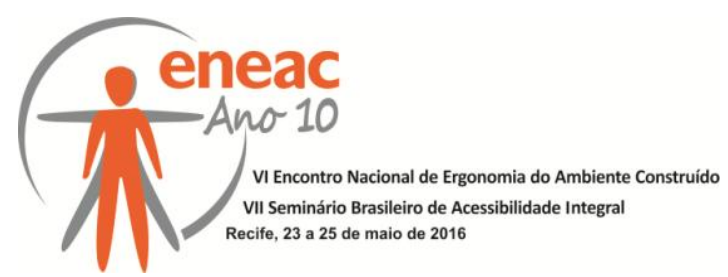

\subsection{Forma}

O templo tem formato radial, com origem no altar, é marcado por ritmo em sua composição, com movimento e repetição dos elementos arquitetônicos. A forma do projeto é simbólica. A localização do altar, na sua proporção e elevação na fachada, conduz à espiritualidade e pode ser representado pela união das mãos em atitude de oração. A forma da laje prejudica o escoamento da água da chuva, provocando infiltrações e goteiras.

Figura 3 - a) Criação de movimento; b) Simbolismo; c) e d) Repetição.

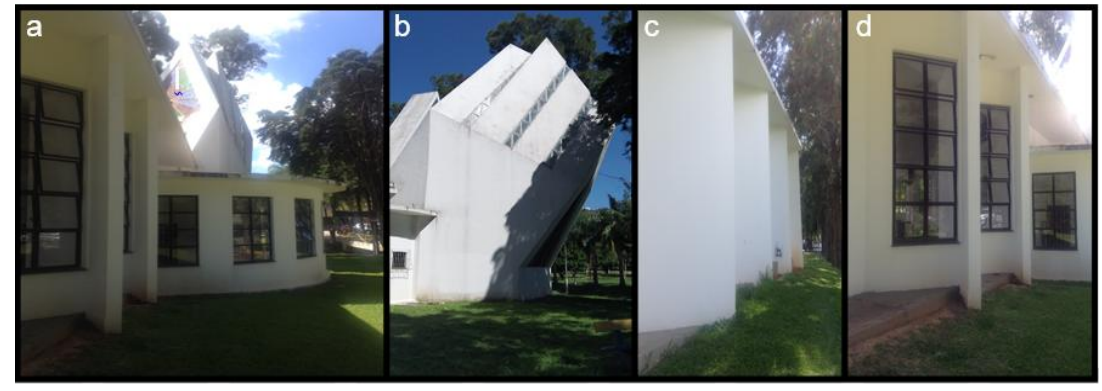

Fonte: elaborada pelas autoras, 2014.

\subsection{Acessos}

O templo é envolto por vegetação, minimizando a radiação solar direta. O pergolado relaciona interior e exterior, e é um local onde os usuários gostam de permanecer. O fluxo primário é central, acessado pela parte frontal do templo, conduzindo os usuários ao altar. Os acessos secundários são laterais. As larguras mínimas das circulações são respeitadas de acordo com as normas exigidas pela Prefeitura Municipal de Florianópolis e pelo Corpo de Bombeiros e, quanto à largura, atendem o conforto dos usuários. A segurança nos acessos, porém, é prejudicada pela inclinação das rampas/corredores, que apresentam uma inclinação longitudinal de $11,21 \%$, acima do permitido pela legislação vigente. A acessibilidade é interrompida por barreiras - degraus - nos acessos aos espaços como: o altar, os sanitários, a sala de apoio e patamares.

Figura 4 - a) Acessos e circulação; b) Acesso principal; c) Acesso secundário; d) degraus de acesso aos patamares.

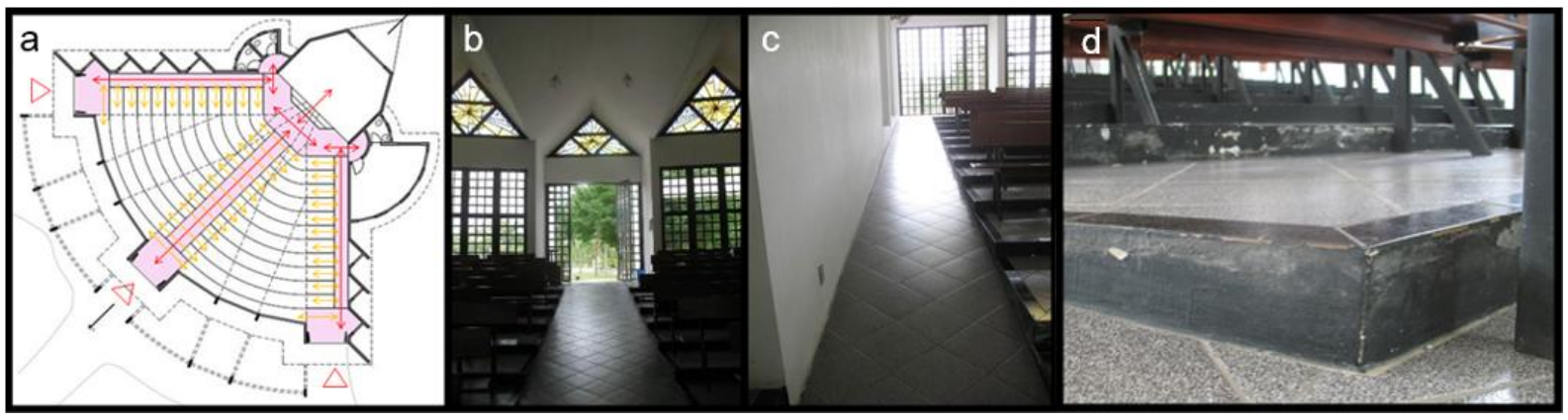

Fonte: elaborada pelas autoras, 2014.

\subsection{Aberturas}

As aberturas, algumas de madeira e vidro, outras de ferro e vidro, marcam uma forte ligação interior/exterior, e, por outro lado, favorecem ofuscamento e excessiva troca térmica, prejudicando o conforto térmico do ambiente. Os vitrais coloridos, dispostos ao fundo e na porção superior do altar, bem acima do local de preleção, marcam pela reflexão dos raios solares, dissipando luz colorida com efeito simbólico, relacionado ao divino e ao sagrado. 


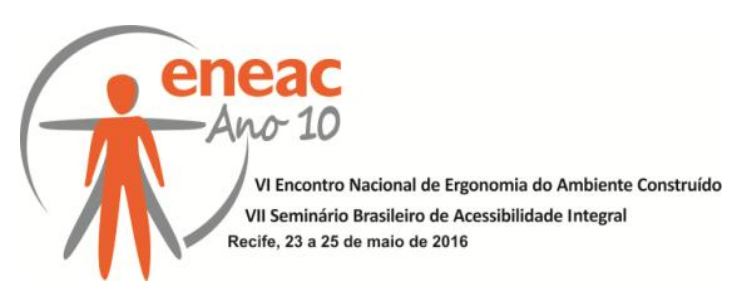

Figura 5 - a) Esquadrias do interior do templo; b) Vitrais do altar; c) Esquadrias dos sanitários.

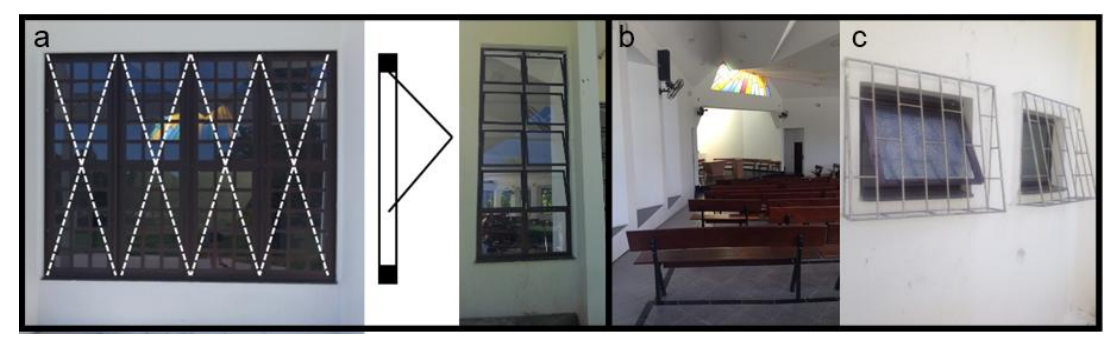

Fonte: elaborada pelas autoras, 2014.

\subsection{Distribuição do layout}

O layout é distribuído radialmente, possibilitando a contemplação do altar, ponto focal do ambiente. Não existe um layout fixo, podendo este ser adaptado pelos usuários, sendo, por um lado, uma vantagem. Por outro, a flexibilidade é desconfortável: nem sempre os bancos estão no "lugar", pois são rearranjados pelos usuários do serviço religioso anterior. Outra dificuldade é que nem sempre todo o mobiliário litúrgico, afora os bancos, é utilizado em uma cerimônia e, durante o seu "não-uso", não há onde possa ser armazenado, sendo. Depositados na sala de apoio. Outro problema em relação ao layout é a distribuição dos sanitários, dispostos junto ao altar, impossibilitando privacidade no uso e tirando a atenção das pessoas da congregação durante os serviços religiosos.

Figura 6 - a) Sala de apoio; b) Layout: sanitários, altar e sala de apoio.

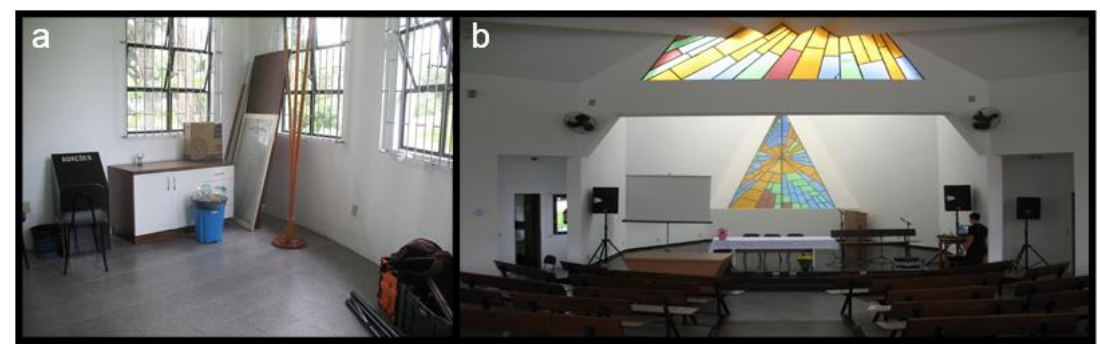

Fonte: elaborada pelas autoras, 2014.

\subsection{Mobiliário}

Os bancos são retos, dispostos em layout curvo, ocasionando quinas que interferem na acomodação e mobilidade. Mesas, púlpitos, ofertórios e demais mobiliários sagrados estão diretamente ligados à liturgia de cada denominação, e sua utilização é feita por poucas pessoas, e por esta razão, não foram analisados neste estudo. Os assentos que acomodam a congregação são compostos por bancos soltos, que se apresentam em dois tamanhos, nas seguintes quantidades: 56 bancos de 180 centímetros de comprimento e 62 bancos de 120 centímetros de comprimento. Os bancos são estruturados em tubos metálicos (aço doce), pintados com tinta automotiva na cor preto, e nesta estrutura são fixadas pranchas de madeira (angelim) tanto para o assento quanto para o encosto. A estrutura, metálica, não apresenta fechamento na extremidade, nem proteção do tipo feltro, de maneira que durante o uso, na interação com um piso não nivelado, no assentar e levantar das pessoas, vários ruídos de metal batendo/arrastando no piso cerâmico são gerados, afetando o conforto acústico. O conforto dos usuários ao utilizarem os bancos é bastante prejudicado, na medida em que os serviços religiosos podem ter longa duração e que os assentos e encostos não são estofados. A segurança durante o uso dos bancos também é prejudicada, pois os bancos são coletivos, lineares, leves e soltos, conforme indicado na Figura 7. Dessa maneira, quando um grupo de pessoas está sentado e quase todos levantam, exceto uma 


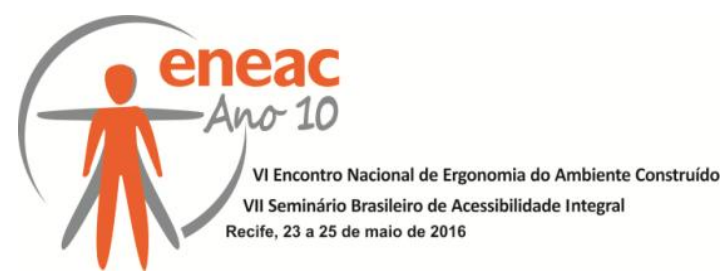

das pessoas, sentada em uma das extremidades, o banco tende a virar. Este fato ocorre frequentemente, levando especialmente pessoas mais idosas, com menor reflexo, a caírem.

Figura 7 - a) Mobiliário do altar; b) Bancos da congregação; c) Croquis dos bancos.

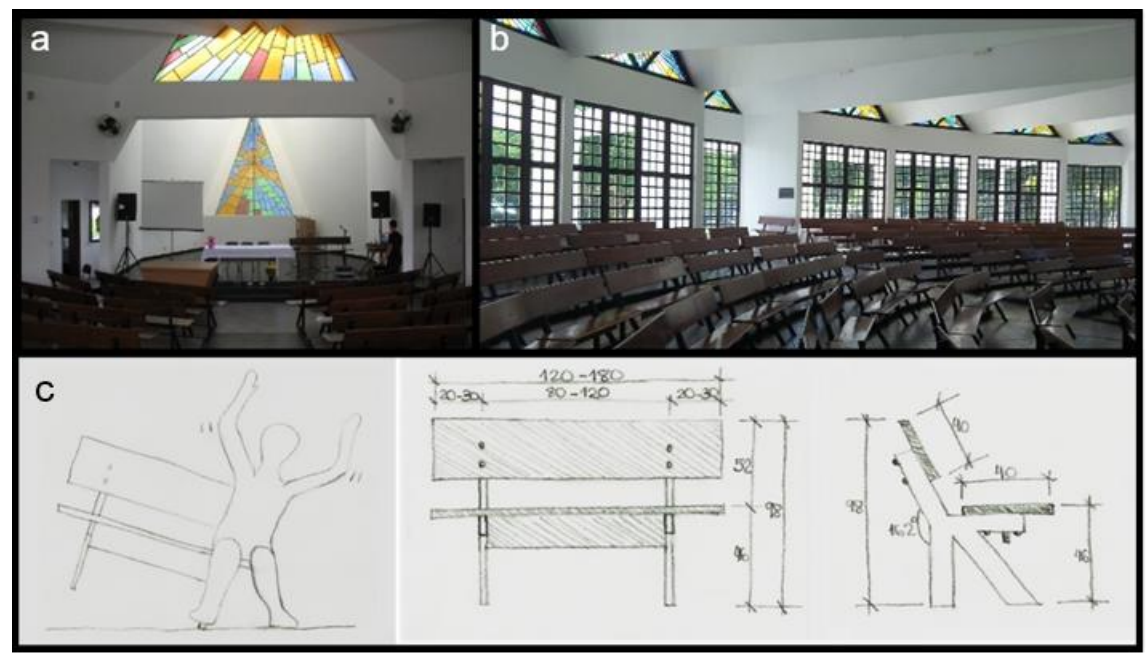

Fonte: elaborada pelas autoras, 2014.

\subsection{Equipamentos}

Entre os equipamentos, pode-se citar os ventiladores, caixas de som, painel para projetar imagens do Datashow. Os ventiladores são um auxílio para amenizar o calor, porém geram ruídos, atrapalhando as atividades. Os ruídos são multiplicados em função da solução formal da planta, que à primeira vista dá uma primeira impressão proporcionar boa distribuição sonora. Esta é uma falsa ideia, pois a área do altar/preleção e de coral fica numa "concha" retirada do corpo em leque que abriga o público, fazendo com que o som emitido pelas pessoas que estão conduzindo a programação - sacerdotes, líderes e músicos - seja desperdiçado, "detido" na "concha". A volumetria também não colabora: é multifacetada - sanfona em leque no teto e em escamas nas laterais. Assim, o som emitido na área da congregação é quase sempre considerado ruído: as exceções são os sons dos hinos ou das orações e responsivos, mas conversas e som de ventiladores são ruídos. Necessariamente se usa som amplificado eletronicamente, nem um coral de 120 vozes gera volume sonoro suficiente para ser apreciado. As leituras espaciais realizadas durante o uso mostraram que mesmo com amplificação, a compreensão dos sons é dificultada, pois a reverberação é bastante alta e o eco sobreposto multiplicadas vezes, causam confusão sonora. Observou-se a falta de espaço adequado para a utilização dos demais equipamentos, ainda mais pela necessidade de sua colocação/retirada em qualquer evento.

Figura 8 - a) Ventilação mecânica; b) Telão de projeção; c) Caixa de som.

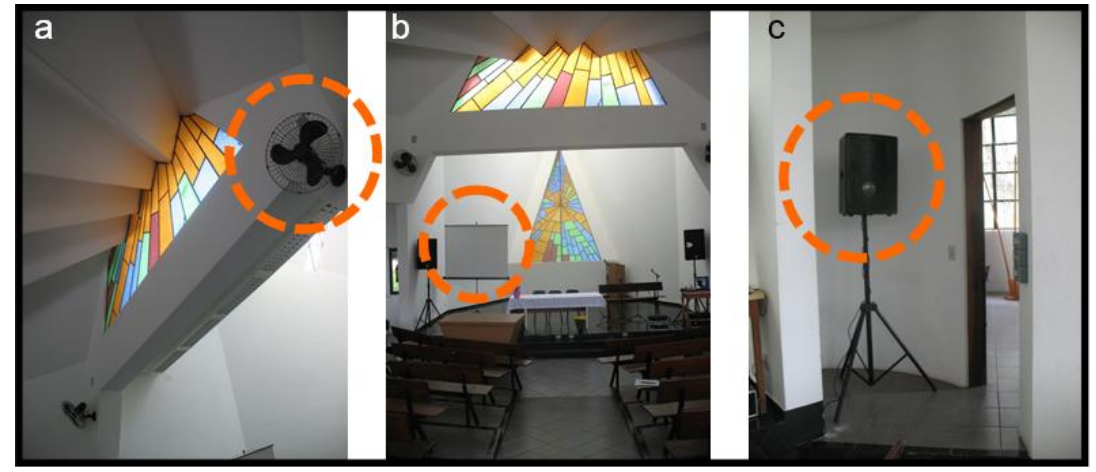

Fonte: elaborada pelas autoras, 2014. 


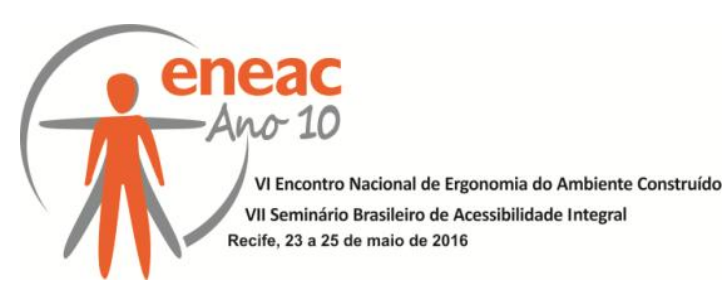

\subsection{Iluminação artificial}

O templo possui contato com o ambiente externo por quase todo o perímetro, através das fachadas envidraçadas e por partes da cobertura. Muitas das atividades são realizadas no período do dia e a iluminação natural inunda o prédio. A iluminação zenital dos vitrais é rica de significados. A iluminação artificial é disposta de acordo com a angulação da cobertura.

Figura 9 - a) Planta de iluminação; b) lluminação do altar; c) Luminárias da nave; d) Croqui de luminária da nave.

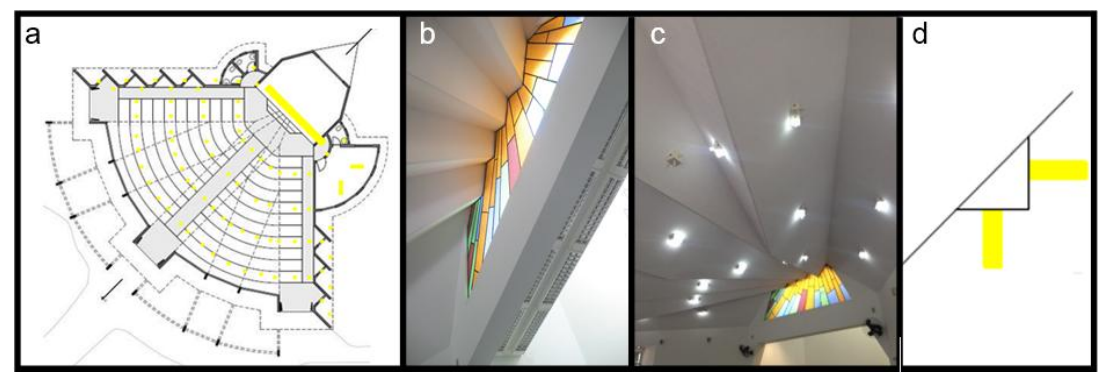

Fonte: elaborada pelas autoras, 2014.

\subsection{Materiais e revestimentos}

Materiais e Revestimentos são atributos que conformam a ambiência, com forte apelo aos aspectos estéticos, ligados ao estilo de vida. Esta dissociação estético-funcional é apenas uma questão classificatória, pois aspectos funcionais e estéticos se relacionam, interagem, são absolutamente indissociáveis. Os revestimentos, materiais e esquema cromático foram sintetizados e são apresentados no Quadro 1, elencados em numeração correspondente àquela disposta sobre a Figura 10, dispostos abaixo, seguidos de um texto explicativo.

Quadro 1 - Materiais, revestimentos e Esquema Cromático e suas principais características.

\begin{tabular}{|c|c|c|c|c|}
\hline ELEMENTO ARQUITETÔNICO & MATERIAL & COR & TOM & SUPERFÍCIE \\
\hline 01 - Teto & Lage maciça & Branco & Claro & Fosco \\
\hline 02 - Paredes & $\begin{array}{l}\text { Alvenaria: } \\
\text { reboco com areia fina }\end{array}$ & Branco & Claro & Fosco \\
\hline 03 - Piso & Piso cerâmico não-antiderrapante & Cinza & Médio & Leve Brilho \\
\hline 04 - Janelas Nave & Alumínio anodizado e vidro & $\begin{array}{r}\text { Marrom e } \\
\text { Transparente }\end{array}$ & Escuro/transparente & Brilho \\
\hline 05 - Vitrais Nave & Ferro e vidro & Colorido & Multitons & Leve Brilho \\
\hline 06 - Mobiliário - Estrutura Bancos & Ferro com pintura eletrostática & Preto & Escuro & Acetinado \\
\hline 07 - Mobiliário - Assentos Bancos & Madeira - angelim pedra & $\begin{array}{l}\text { Amadeirado } \\
\text { avermelhado }\end{array}$ & Médio & Leve Brilho \\
\hline
\end{tabular}

Fonte: elaborada pelas autoras, 2014.

Figura 10 - Materiais do Templo Ecumênico.

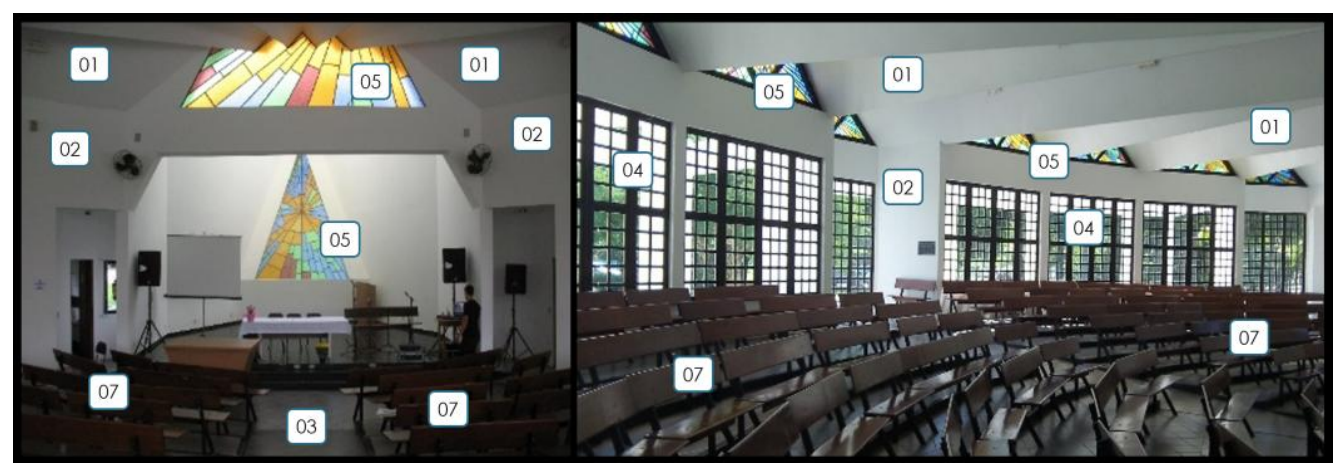

Fonte: elaborada pelas autoras, 2014. 


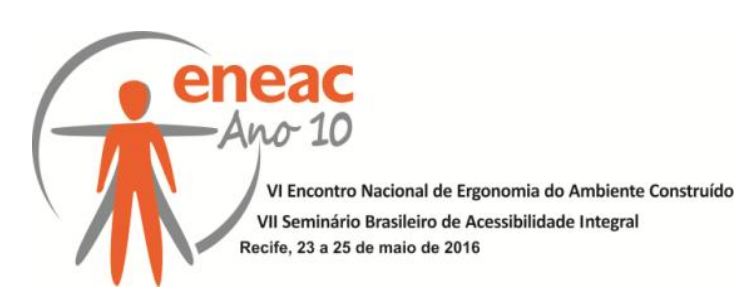

Tanto o interior quanto o exterior do templo apresentam teto (01) e paredes (02) pintadas em branco, auxiliando a reflexão da luz, simbolizando a pureza, causando, contudo, ofuscamento. O piso cerâmico (03) nas rampas é de fácil manutenção, no entanto, em toda a área do templo, em função da infiltração da água pela laje, existem goteiras, especialmente na área das rampas/corredores de acesso, configurando risco aos usuários de caírem e de se machucarem. Seu revestimento liso, sem antiderrapante e em mau estado de conservação, apresentando trechos quebrados, associados à inclinação inadequada, agrava ainda mais o problema.

As janelas (04) são fatores geradores de outro problema acústico. Ainda que a edificação fosse bem isolada quando fechada, no verão a vedação não seria eficiente, uma vez que o calor desta época exige janelas abertas. Este fato se configura num problema grave toda vez que tem um serviço religioso concomitantemente a um evento externo com forte emissão sonora, a exemplo de shows que ocorrem na Concha Acústica, além de festas e feiras que ocorrem em frente à Reitoria. Abertas ou fechadas, as janelas, assim como os vitrais (05) são elementos que se apresentam em quantidade expressiva, e tem materiais "duros", refletivos, acusticamente falando.

O mobiliário principal é o conjunto de bancos de metal (06) e madeira (07). A madeira em si, confere um ar tranquilo ao espaço, mas não colabora nem com o conforto háptico e nem com o conforto acústico, como seria o caso de assentos e encostos estofados. A estrutura metálica pintada em preto não interfere visualmente, e pouco acusticamente, exceto pela associação com o piso desnivelado e por pontas junto ao piso sem proteção. No todo, apesar dos bancos proporcionarem boas características térmicas, além dos já citados problemas, não apresentam conforto antropométrico.

Os materiais de revestimentos como um todo, não colaboram com o desempenho acústico. Todos são materiais "duros" - refletivos sonoros. Não há materiais absorventes, por esta razão, ainda que amplificado eletronicamente, muitas vezes o som não é claramente compreendido. Este fato se dá porque quanto mais a equipe de sonoplastia aumenta o volume do som, mais a reverberação é percebida, com a percepção de eco prolongado. Numa sequência de palavras e/ou harmonias musicais, os novos sons emitidos vão sucessivamente se sobrepondo, tornando a compreensão tanto mais difícil quanto menor for o número de pessoas presentes. Quanto mais pessoas presentes, representando os corpos e as roupas materiais menos "duros", mais este fator é atenuado.

\section{SÍNTESE DA ANÁLISE}

O Quadro 2, disposto abaixo, apresenta a síntese da análise da ambiência realizada no Templo Ecumênico da UFSC. São expostas na primeira coluna, as atividades avaliadas, na coluna central, os elementos arquiteturais avaliados e, por fim, na terceira coluna, os conflitos encontrados. 


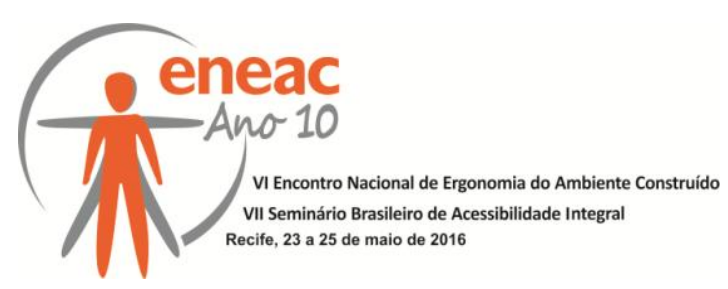

Quadro 2: Tabela síntese da análise - conflitos entre elementos e atividades.

\begin{tabular}{|c|c|c|}
\hline ATIVIDADE & ELEMENTO & CONFLITO \\
\hline \multirow{4}{*}{$\begin{array}{l}\text { Acessar e circular } \\
\text { pela nave }\end{array}$} & Degraus e rampas & Desníveis e inclinações versus dificuldade/impossibilidade de acesso \\
\hline & Revestimentos & Superfícies lisas e molhadas versus pisos escorregadios \\
\hline & Laje & Impermeabilização da laje versus infiltração e gotejamento \\
\hline & Corrimãos & Ausência de corrimãos versus dificuldade/impossibilidade de circulação \\
\hline \multirow{3}{*}{ Sentar } & \multirow{3}{*}{ Mobiliário } & Desenho do mobiliário versus conforto antropométrico \\
\hline & & Desenho do mobiliário versus segurança \\
\hline & & $\begin{array}{r}\text { Incompatibilidade do mobiliário com o layout versus conforto } \\
\text { antropométrico }\end{array}$ \\
\hline \multirow{3}{*}{$\begin{array}{l}\text { Falar a partir do altar/ } \\
\text { Escutar desde a nave }\end{array}$} & Forma & Alturas de pé direito versus propagação do som \\
\hline & Revestimentos & Revestimentos refletivos versus reverberação do som \\
\hline & Layout & Localização dos sanitários versus dispersão de atenção visual e acústica \\
\hline \multirow{2}{*}{ Exibir slides } & Tela de projeção & \multirow{2}{*}{ Superfície de projeção versus conforto antropométrico } \\
\hline & Layout & \\
\hline \multirow{2}{*}{$\begin{array}{l}\text { Permanecer no ambiente } \\
\text { por longo período }\end{array}$} & Janelas & Orientação das aberturas versus conforto térmico \\
\hline & Ventiladores & Utilização dos ventiladores versus conforto acústico \\
\hline \multirow{3}{*}{$\begin{array}{l}\text { Orar/Interiorizar/ } \\
\text { Concentrar/Refletir } \\
\text { Armazenar equipamentos }\end{array}$} & Janelas & Excesso de iluminação natural e permeabilidade visual versus intimidade \\
\hline & Revestimentos & Revestimentos refletivos versus reverberação do som \\
\hline & Layout & Ausência de depósito versus desorganização de ambiente de apoio \\
\hline Reunir grupos & Layout & Número insuficiente de salas de apoio versus reuniões de grupos \\
\hline
\end{tabular}

Fonte: elaborada pelas autoras, 2014.

\section{CONSIDERAÇÕES FINAIS}

As interações entre as pessoas e os espaços arquiteturais nas suas implicações com os elementos arquitetônicos e com as atividades naquele espaço desenvolvidas, demonstraram que os conflitos observados revelam fenômenos existenciais de ambiência, que se relacionam com determinados elementos arquitetônicos.

No Templo Ecumênico da UFSC, os aspectos subjetivos geram menos conflitos que os objetivos, ou seja, o tempo transmite ao usuário o caráter inerente à sua função: contemplação e espiritualidade. A obra arquitetônica é impregnada de simbolismo, alcançado principalmente pela sua forma e pela utilização de vitrais.

Já os aspectos objetivos referentes à técnica construtiva e manutenção da obra apresentam deficiências que interferem na usabilidade e em alguns aspectos subjetivos.

As características lumínicas, acústicas e térmicas da obra apresentam problemas técnicos tais como excesso de iluminação, causando ofuscamento, interferência na distribuição do som no ambiente, e sensação de calor que atrapalha na concentração e na meditação do usuário, o que compromete a vivência do espaço pelo usuário.

O equilíbrio entre os aspectos objetivos e subjetivos da ambiência conferem ao espaço o caráter de arquitetura - arte, técnica, usabilidade, etc. Assim, a ambiência desejada nos espaços, deve atender estes dois aspectos, pois diretamente ligados, interferem na percepção e sensações que as pessoas têm nos espaços.

\section{REFERÊNCIAS BIBLIOGRÁFICAS}

ALMEIDA, Maristela Moraes de. Análise das relações entre o homem e o ambiente: estudo de caso em agência bancária. Orientação de Fernando Oscar Ruttkay Pereira. Brasil - Florianópolis, SC. UFSC. 1995. 126p. Dissertação (Pós-graduação em Engenharia de Produção) - Universidade Federal 


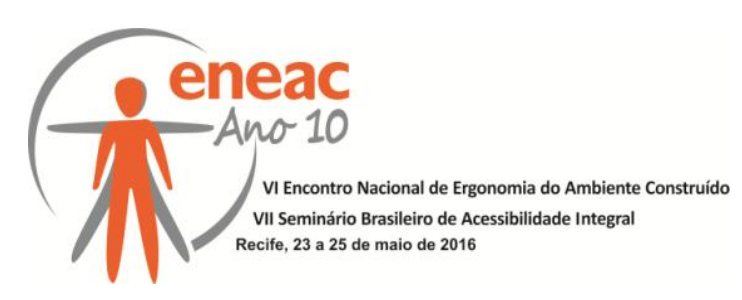

de Santa Catarina, 1995

ALMEIDA, Maristela Moraes de. Da experiência ambiental ao projeto arquitetônico: um estudo do caminho do conhecimento na arquitetura. Orientação de Fernando Oscar Ruttkay Pereira. Brasil Florianópolis, SC. UFSC. 2001. 219p. Tese (Pós-graduação em Engenharia de Produção) Universidade Federal de Santa Catarina, 2001.

ALMEIDA, Maristela Moraes de. Anotações da disciplina Atributos dos Elementos Arquitetônicos e suas Relações com a Habitabilidade e a Sustentabilidade. Florianópolis, UFSC, Programa de Pós Graduação em Arquitetura - PósARQ, 3o trimestre de 2014.

BAUDRILLARD, Jean. The System of Objects. Translated by James Benedict. London: 1996.

HEIDEGGER, M. Poetry, Language, Thought. Traduzido para o inglês por Albert Hofstadter. New York: Harper \& Row Publishers, 1971.

HEIDEGGER, Martin. Ser e tempo. 5. ed. Petrópolis: Vozes, 1997.

MALARD, M. L. Brazilian low-cost housing: interactions and conflicts between residents and dwellings. Sheffield: University of Sheffield. Ph. D. Thesis, 1992.

MALARD, Maria Lúcia. As aparências em Arquitetura. Belo Horizonte: Editora UFMG, 2006. 